DOI: https://doi.org/10.24867/05AM04Vidovic

\title{
POLIMERNI MATERIJALI U MEDICINI I FARMACIJI I POSTUPCI NJIHOVE PRERADE
}

\section{POLYMER MATERIALS IN MEDICINE AND PHARMACY AND PROCEDURES OF THEIR PROCESSING}

\author{
Vanja Vidović, Mladomir Milutinović, Fakultet tehničkih nauka, Novi Sad
}

\section{Oblast - MAŠINSTVO}

Kratak sadržaj - Polimerni materijali jedni su od najvažnijih materijala koji se koriste u medicini $i$ farmaciji. U radu je dat prikaz materijala koji se najčešće upotrebljavaju, njihove osobine kao i primeri njihove primene u praksi. Takođe, opisani su postupci prerade ovih materijala.

Ključne reči: polimeri, biomaterijali, postupci prerade, injekciono presovanje, ekstrudiranje, kalandriranje.

Abstract - Polymer materials are one of the most important materials used in medicine and pharmacy. The paper presents the most frequently used materials, their properties and application in practice. Also, procedures for processing these materials are described.

Keywords: polymers, biomaterials, processing methods, injection molding, extrusion, calendaring

\section{UVOD}

Druga polovina prošlog i početak ovog veka obeleženi su intezivnim razvojem tehnologije proizvodnje baznih plastičnih (polimernih) materijala i prerade u elemente različitog upotrebnog karaktera. Nove formulacije poznatih hemijskih jedinjenja i novih struktura aditiva, jednostavan i brz postupak oblikovanja, stvorili su ogroman prostor za korišćenje elemenata od polimera u svim segmentima industrije i u svakodnevnom životu. Najveći broj predmeta koji okružuje svakog čoveka u bilo kojoj zemlji i na bilo kojem kontinentu izrađen je, delom ili celosti, od nekog polimernog materijala. Zamenjuje drvo, aluminijum, čelik, staklo, tekstil, kožu i druge prirodne materijale. [4]

Tako masovno područje primene polimernih materijala stvorilo je osnovu za neverovatno brz razvoj raznih tehnologija prerade polimernih materijala i mašina koje je prate, a u okviru toga, razvoj konstrukcija i materijala od kojih se proizvode alati, hidraulike koja ih pogoni, robota koji opslužuju mašine i elektronike koja upravlja celokupnim tehnološkim postupkom. Takođe, polimeri se smatraju važnim medicinskim i farmaceutskim materijalom iz određenih razloga kao što su: kompatibilnost i sposobnost da izdrži dugotrajno izlaganje ljudskom telu, biodegradabilnost, mala težina, lakoća izrade i upotreba. Detaljan opis materijala kao i njihova primena prikazana je $\mathrm{u}$ nastavku teksta.

\section{NAPOMENA:}

Ovaj rad proistekao je iz master rada čiji mentor je bio dr Mladomir Milutinović, vanr. prof.

\section{POLIMERNI MATERIJALI I NJIHOVA PRIMENA}

Polimeri su organska ili neorganska jedinjenja izgrađena od molekula velikih molekulskih masa (makromolekula) u kojima su atomske grupe, tzv. "strukturne jedinice", povezane hemijskim vezama čineći tako polimerni (makromolekulski) lanac. Prilikom odabira polimernog materijala treba voditi računa o strukturi polimera, hemijskom sastavu i fizičkom stanju jer oni utiču na svojstva polimera. Neka od svojstava i zahteva polimernih farmaceutskih i medicinskih materijala su [3]:

- čisti materijali

- lako preradljivi

- dugoročno raspoloživi

- imaju raspoložive sertifikate zdravstvenih organizacija Materijali koji se najčešće upotrebljavaju u medicini i farmaciji su: polietilen (PE), polietilen-tereftalat (PET), polipropilen (PP), polivinilhlorid (PVC), poli-etar-etarketon (PEEK) koji su u detaljno opisani u nastavku teksta. Postoje tri osnovna tipa polietilena: polietilen niske gustine(PE-LD), linearni polietilen niske gustine(PELLD) i polietilen visoke gustine(PE-HD). Polietilen je postojan na veliki broj hemikalija, osim oksidirajućih kiselina, halogenih elemenata i malog broja ketona. Pri sobnoj temperaturi netopljiv je i bubri samo nakon dužeg izlaganja. PE-LD ima dobra svojstva zatezne čvrstoće, savojne žilavosti, a zadržava svoju čvrstoću i do $-60^{\circ} \mathrm{C}$. Kad je izložen ultraljubičastom zračenju, polietilen je podložan procesima hemijske ili toplotne razgradnje. U farmaceutskoj industriji PE-HD se primenjuje za izradu bočica u kojima se nalaze lekovi u čvrstom stanju kao što su npr. tablete, kapsule i sl. Bočice mogu biti različitih dimenzija, oblika i boja. Na slici 2.1 prikazana je bočica cilindričnog oblika.

Polietilen-tereftalat je kondenzacijski polimer, što znači da proces polimerizacije uključuje uklanjanje vode. Žilav je i izvrsne je prozirnosti i sjaja. Lagan je i postojan na napukline zbog naprezanja(tenzokoroziju). Izvrsne je dimenzijske stabilnosti i posjeduje vrlo dobro svojstvo barijernosti na vodenu paru, kiseonik i ugljendioksid. PET se može ojačati staklenim vlaknima da bi se proizvodili injekcijski proizvodi s visokom toplotnom postojanošću i visokom žilavošću. PET bočice nalaze veliku primenu pri izradi bočica za oralnu higijenu. Osim za kapi, u PET bocama se mogu čuvati lekovi u krutom stanju. Tako na primer od PET-a izrađuju se bočice u kojima se čuvaju šumeće tablete. Na slici 2.2 prikazana je PET bočica namenjena čuvanju lekova u krutom stanju. 


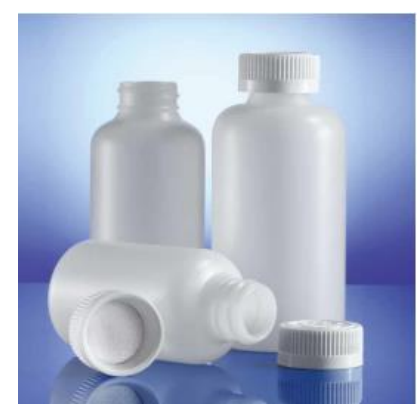

Slika 2.1 PE-HD bočice cilindričnog oblika[2]

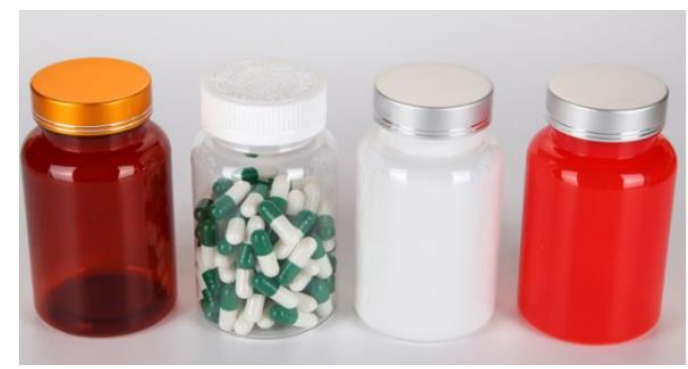

Slika 2.2. PET bočica za lekove[11]

Polipropilen ima mnoga slična svojstva sa polietilenom niske gustine. No, polipropilen ima višu tvrdoću i zateznu čvrstoću, elastičniji je, prozirniji i sjajniji, uz podjednaku propusnost za gasove i pare. Nedostatak polipropilena je niska žilavost, posebno pri nižim temperaturama (već pri $0{ }^{\circ} \mathrm{C}$ postaje $\mathrm{krt}$ ). PP se upotrebljava u razne svrhe $\mathrm{u}$ medicinskoj industriji. Kao materijal za proizvodnju medicinske ambalaže, upotrebljava se za proizvodnju medicinskih šprica, vrećica, jednokratnih komponenti za bolnice, epruveta, čaša i itd. Na slici 2.3 prikazana je šprica od polipropilena.

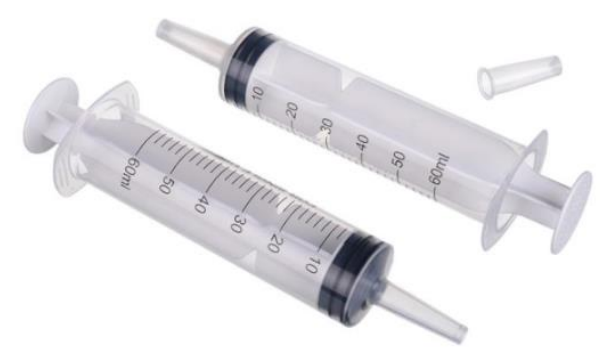

Slika 2.3 Šprica od polipropilena[6]

Zahvaljujući dobroj kompatibilnosti i širokom području primene PVC je materijal koji se najčešće upotrebljava. U farmaceutskoj industriji služi za izradu PVC filmova za (blister) ambalažu, te za izradu bočica različitih oblika i veličine. Na slici 2.4 prikazana je ambalaža s PVC filmom. PVC filmovi moraju biti dovoljno čvrsti i kruti kako bi predstavljali fizičku zaštitu za farmaceutski proizvod. S druge pak strane, istiskivanje proizvoda iz blister ambalaže ne sme biti preteško. Upravo zbog tih razloga debljina PVC filmova iznosi između 0,2 i $0,3 \mathrm{~mm}$ u zavisnosti od veličine i oblika mjehura. [2].

Pored gore navedenih polimera, veliku primenu u izradi medicinske i farmaceutske opreme pronašli su i manje poznati materijali koji pripadaju familiji poli-aril-etarketona, skraćeno PAEK. [9] Iz ove grupe najpoznatiji materijali su PEEK i PEKK. Poslednjih godina, poli-etar- etar-keton (PEEK) je postao sinonim za polimere najviše klase. To je materijal koji se koristi na visokim temperaturama $\left(250^{\circ} \mathrm{C}\right)$ i pokazuje izvanrednu mehaničku čvrstoću, žilavost, savijanje pri čemu može podneti pritisak do 3,6 GPa. Njegove karakteristike upotpunjuje biokompatibilnost, odlična hemijska stabilnost, veoma dobra dielektrična svojstva $\mathrm{i}$ otpornost na gama $\mathrm{i}$ rentgensko zračenje. [8]

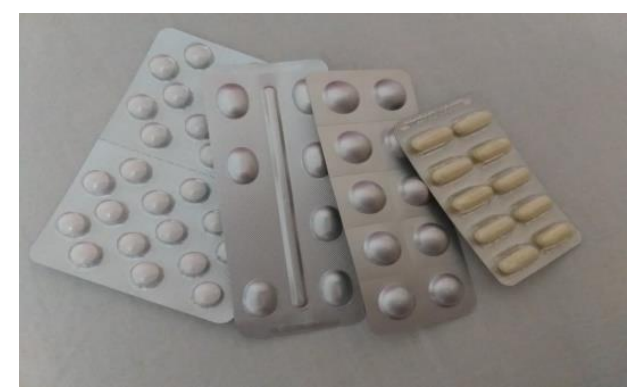

Slika 2.4 Blister od PVC-a

Pored gore navedenih polimera, veliku primenu u izradi medicinske i farmaceutske opreme pronašli su i manje poznati materijali koji pripadaju familiji poli-aril-etarketona, skraćeno PAEK. [9] Iz ove grupe najpoznatiji materijali su PEEK i PEKK. Poslednjih godina, poli-etaretar-keton (PEEK) je postao sinonim za polimere najviše klase. To je materijal koji se koristi na visokim temperaturama $\left(250^{\circ} \mathrm{C}\right)$ i pokazuje izvanrednu mehaničku čvrstoću, žilavost, savijanje pri čemu može podneti pritisak do 3,6 GPa. Njegove karakteristike upotpunjuje biokompatibilnost, odlična hemijska stabilnost, veoma dobra dielektrična svojstva i otpornost na gama i rentgensko zračenje. [8]

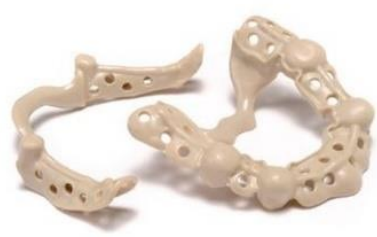

Slika 2.5 Proteza za zube [7]

Naravno, ubrzanim razvojem ove grane industrije dolazi do upotrebe sve većeg broja različitih polimera, od kojih su mnogi još u fazi ispitivanja. Na dijagramu je prikazana upotreba polimera u medicini i farmaciji iz 2016. godine.
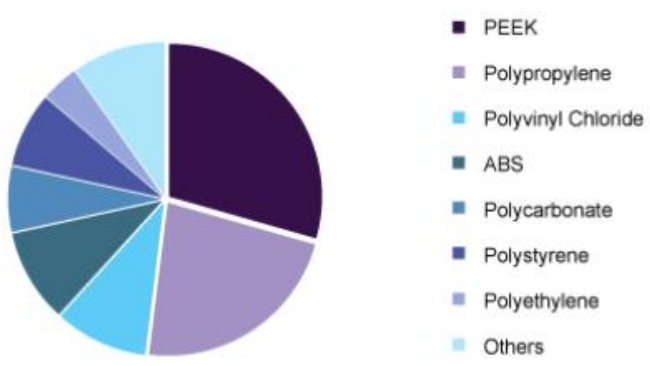

Slika 2.6 Upotreba polimera u medicine i farmaciji[10] 


\section{KLASIFIKACIJA POSTUPAKA PRERADE POLIMERA}

Savremeni proizvodni sistemi u mašinskoj industriji odlikuju se proširenjem asortimana proizvoda, visokom frekvencijom promene programa proizvodnje, zahtevima za stalnim poboljšanjem kvaliteta proizvoda, alata, smanjenjem rokova i troškova njihove izrade, stalnom potrebom podizanja tehnološkog nivoa proizvoda itd. Jedna od najvažnijih karakteristika savremenog proizvodnog sistema jeste sposobnost da se u što kraćem vremenu projektuje i proizvede mnoštvo visokokvalitetnih proizvoda. Brzo lansiranje novog proizvoda na tržište, pre nego što to učini konkurencija, predstavlja ključni faktor u obezbeđivanju većeg dela tržišta i viših profitnih stopa. Ključni aspekt u razvoju proizvoda jesu faze koncepcijskog i detaljnog projektovanja $u$ kojima treba da dođe do stvaranja $\mathrm{i}$ vrednovanja ideja za novi proizvod. [1]

Podela tehnologija za proizvodnju proizvoda od plastike prikazana je na slici 3.1.

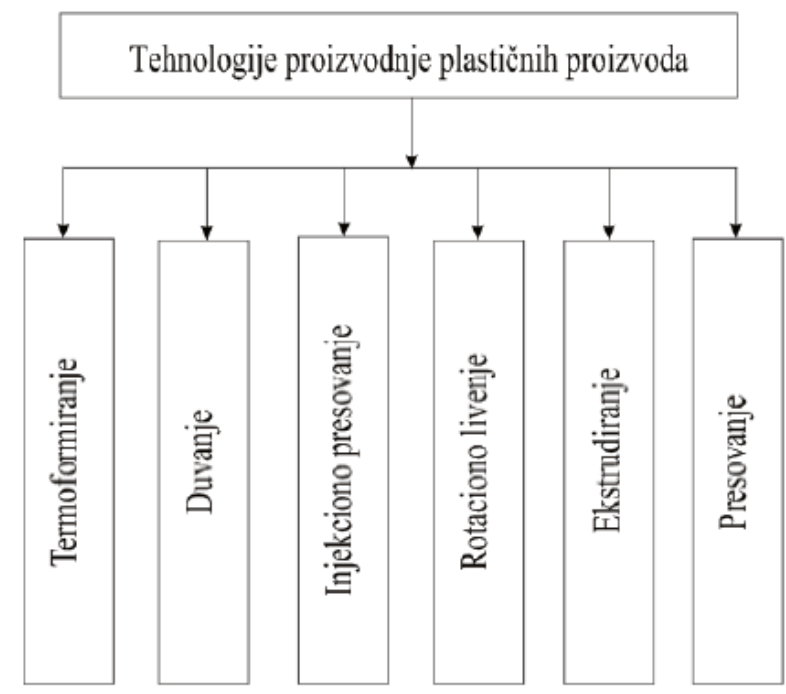

Slika 3.1 Tehnologije prerade polimera[1]

U nastavku teksta opisani su postupci koji se najčešće upotrebljavaju.

Injekciono presovanje je najvažniji ciklični postupak prerade polimera, a prema dostignutoj tehnologiji i najusavršeniji. Ovaj postupak spada u primarnu preradu polimera tj. $\mathrm{u}$ praoblikovanje polimera, jer se oblik otpreska dobija od polaznog materijala koji nema određenu formu (granule, komadići i sl.) Injekcionim presovanjem se oblikuju svi polimeri: duromeri, elastomeri, elastoplastomeri, a posebno je raširena prerada plastomernih materijala. Može se smatrati da je injekciono presovanje polimera slično livenju pod pritiskom metala. Injekcionim presovanjem se osim polimera prerađuju i keramičke smeše, kombinacije različitih materijala (npr. plastika, metal i keramika) i biomaterijali. Ovaj postupak se izvodi ubrizgavanjem rastopljenog polimera određene viskoznosti iz injekcione jedinice u temperiran kalup. Krakto vreme ciklusa, visoka ponovljivost kvaliteta dobijenih otpresaka, visoka dimenziona tačnosti i velika raznolikost otpresaka različite sloţenosti, čini tehnologiju injekcionog presovanja vrlo popularnom u preradi plastike. Glavne prednosti ovog postupka su u velikoj mogućnosti iskorišćenja plastičnog materijala, manjem vremenu izrade proizvoda, visokoj dimenzionoj tačnosti otpreska, i manjem potrebnom prostoru za proizvodnju. [5]
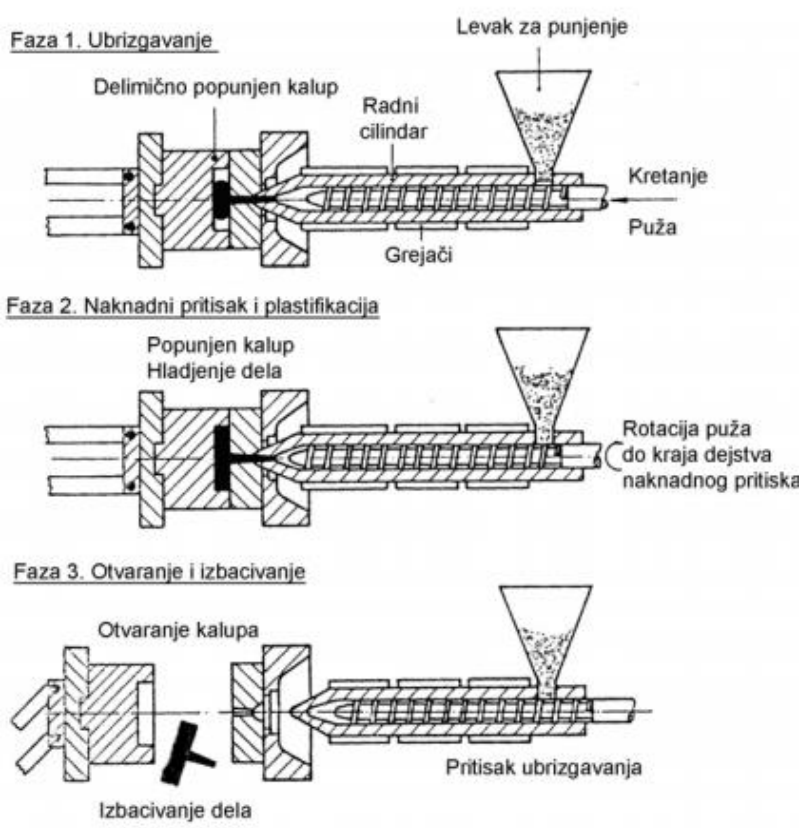

Slika 3.2 Šema procesa injekcionog presovanja[5]

Ekstrudiranje je kontinualni postupak prerade plastičnih masa. Ovim postupkom plastična masa, kao polazna sirovina, u prahu ili što je najčešće u granulatu raznih oblika ubacuje se putem levka u cilindar mašine u kojoj je smešten jedan ili više puževa koji plastičnu masu transportuju, a pod uticajem dovedene toplote prevode je u tečno stanje. Dejstvom pogona za obrtanje puža kao i savlađivanjem otpora koji nastaju transportovanjem rastopljene plastične mase, kroz otvore između puža i cilindra masa se plastificira, homogenizuje i na kraju u alatu mašine formira u željeni oblik. Ova mašina u kojoj se odvija pomenuti proces prerade plastike zove se ekstruder i prikazana je na slici 3.3.

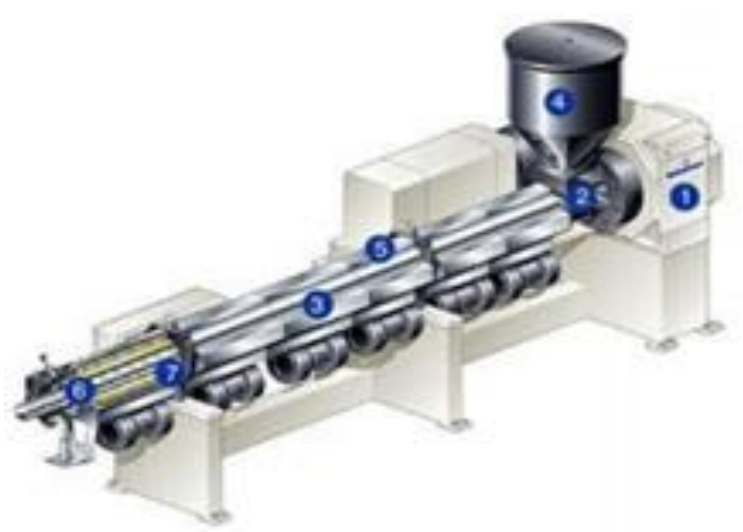

Slika 3.3 Jednopužni ekstruder[5]

Jednopužni ekstruder sastoji se od:

1) puža, 2) cilindara, 3) spojnica za spajanje sa alatom, 4) vodeno hlađene ulazne zone, 5) levka za doziranje sirovina, 6) pogona ekstrudera, 7) temperiranje puža. 
Ekstruderi sa jednim pužem imaju veliku primenu u preradi polimera, a prednost ovih mašina $u$ odnosu na druge su:

- niža cena,

- jendostavna, robusna i pouzdana konstrukcija,

- dobre tehničke performanse

Ekstrudiranjem se u farmaceutskoj industriji uobičajeno izrađuju bočice manjih dimenzija kao što je bočica u kojoj se nalaze kapi za oči.

Kalandriranje je kontinualan postupak izrade beskonačnih traka praoblikovanjem visoko viskoznog rastopljenog polimera njegovim propuštanjem između parova valjaka kalandra s prilagodljivim zazorom. Obradak, kalandrat $\mathrm{u}$ obliku traka nastaje očvršćivanjem procesima geliranja i hlađenja, hlađenja ili umrežavanja. Kalandriraju se smeše od prirodnog i sintetičkog kaučuka i plastomera. Kalandriranje plastomera počelo je najpre sa smešama poli(vinil-hlorida), što je i danas najčešće prerađivani polimer tim postupkom (60\% svih kalandrata) [5]

Najvažniji element linije za kalandriranje jeste kalandar. Osnovna uloga kalandra je da delovanjem pritiska razvalja na potrebnu debljinu dobavljeni prethodno omekšani polimer. Kalandri se razlikuju prema broju valjaka i njihovom međusobnom položaju. Prema broju valjaka mogu biti: dvovaljčani do peterovaljčanih, a prema položaju valjaka razlikuje se I, F, L, Z i S izvedba, što se vidi na slici 3.4

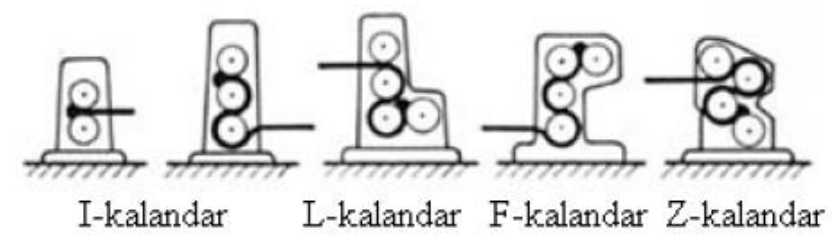

slika 3.4 Kalandar

\section{ZAKLJUČAK}

Kada je u pitanju primena u medicini može se zaključiti da polimerni biomaterijali pokazuju značajne prednosti u odnosu na ostale materijale. Prednosti polimernih materijala su u tome što su vrlo biokompatibilni, mogu se lako izraditi u proizvode raznih oblika, mogu se reciklirati i imaju povoljne mehaničke i fizičke osobine. Od velike je važnosti da izrada i obrada pomenutih materijala bude precizna i čista, kako bi se mogućnost za neke poremećaje $\mathrm{u}$ organizmu, npr.trovanje i slično svele na najmanju moguću meru. Takođe, bitno je da tokom obrade ne dolazi do hemijskih ili mehaničkih promena u samom materijalu. Polimerni materijali, kao i svi drugi materijali imaju svoje prednosti i nedostatke pa samim tim imaju i ograničenost u primeni. Medicina je opširno područje, a zastupljenost polimernih materijala u medicini je vrlo velika. Kako se medicina razvija tako se i zahtevi prema polimernim materijalima sve više povećavaju. U radu je napravljen pregled polimernih materijala koji su najviše i najčešće u upotrebi, a to su oni materijali koji svojim svojstvima najbolje odgovaraju sve strožijim postavljenim zahtevima sa aspekta sigurnosti, biokompatibilnosti i hemijske postojanosti. Proizvodi od plastike danas znatno pridonose kvalitetu života te očuvanju prirodnih resursa $\mathrm{i}$ klime, stoga je plastika važna u industriji. Svakodnevno veliki broj stručnjaka radi na razvoju novih materijala koji imaju sve bolja mehanička i termička svojstva, duži vek trajanja te manji uticaj na okolinu. Tako su sigurnosni i zdravstveni zahtevi te zahtevi zaštite okoline doveli do razvoja novih nanomaterijala, biorazgradljivih te biokompatibilnih polimernih materijala. Razvijaju se novi postupci prerade polimera, te se poboljšavaju postojeći preradbeni postupci u svrhu poboljšavanja kvaliteta proizvoda, smanjenja potrošnje prirodnih izvora sirovina te očuvanja okoline. Ekonomski zahtevi, zakoni o zaštiti okoline, niski troškovi proizvodnje, skraćenje vremena od dizajna proizvoda pa do njegovog izlaska na tržište, zahtevi su koji teraju proizvođače da proizvode kvalitetnije, jeftinije i brže. Zbog tih sve većih zahteva proizvođači nastoje koristiti materijale, proizvodne postupke i opremu koja je u skladu sa zadatim zahtevima te koja će skratiti proizvodni ciklus, proizvoditi kvalitetnije proizvode, imati manji utrošak energije, manje zagađivati okolinu, a sve će to rezultirati smanjenjem cene samog proizvoda.

\section{LITERATURA}

[1] Matin, I.: Modularni sistemi za projektovanje alata za injekciono presovanje plastike, Univerzitet u Novom Sadu, Fakultet tehničkih nauka, Novi Sad, 2011.

[2] Pavlinec, M.: Razvoj plastične ambalaže za pakovanje farmaceutskog proizvoda, Sveučilište u Zagrebu, Fakultet strojarstva i brodogradnje, Zagreb, 2017.

[3] Stojiljković, D., Pilić, B.: Struktura i svojstva polimernih materijala, Univerzitet u Novom Sadu, Tehnološki fakultet, Novi Sad, 2007.

[4] Savić, V.: Osnovni mehanizmi hlađenja mašina za prizganje plastike pod pritiskom, Požega, 2009.

[5] Vilotić, D. Tehnologija injekcionog presovanja p olimera, Univerzitet u Novom Sadu, Fakultet tehničkih nauka, Novi Sad, 2007.

[6] http://ru.goldenwellgermany.com/disposablesyringe/irrigation-syringe/plastic-100ml-irrigation-syringe

[7] http://dental4u.ba/aktuelnosti-izstomatologije/clanci/peek-polyether-ether-ketone/

[8] https://www.termoplast.rs/tehnicka-plastika/termoplastpeek $\mathrm{t}$

[9] https://www.dental-medical.rs/blog/peek-vs-pekk,

[10] https://www.grandviewresearch.com/industryanalysis/medical-plastics-market

[11] http://srla.fukang-jars.com/plastic-jar/shenzhen-port-petpill-bottle-storage-in.html

\section{Kratka biografija:}

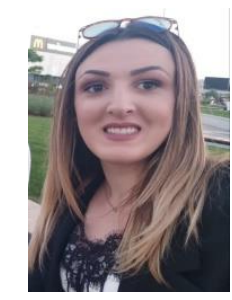

Vanja Vidović rođena je u Vlasenici 1994 godine. Diplomirala na Fakultetu tehničkih nauka smer Proizvodno mašinstvo 2018. god. Master studije upisala iste godine na usmerenju Savremene tehnologije oblikovanja plastike.

Mladomir Milutinović rođen je u Arilju 1967.godine Doktorirao je na Fakultetu tehničkih nauka 2013.god., iste godine izabran je u zvanje docenta. Oblast interesovanja su tehnologije plastičnog deformisanja, aditivne i virtuelne tehnologije 